Amazonía Peruana, Volumen XVII, № 34, 2021; pp. 219-232

\title{
LOS ENUNCIADOS EXPRESIVOS Y CANCIONES ANCESTRALES YANESHA Y SU APLICACIÓN EN LA EDUCACIÓN INTERCULTURAL BILINGÜE
}

\author{
Izhar Dionicio Antazú \\ Maestría en EIB, GI EILA-UNMSM \\ izhar.dionicio@unmsm.edu.pe \\ (1) https://orcid.org/0000-0003-4129-7077
}

\section{Resumen}

Las canciones ancestrales son un conjunto de versos, melodías y ritmos propios de un pueblo originario. Son diversas: konareñets, sherareñets, rekërkënets, etseñets, wellesheñets, po'neshareteñets. Se transmiten de generación en generación de forma oral con la finalidad de mantener y enriquecer la cultura. Centraremos nuestra atención en los enunciados expresivos que se pueden evidenciar al inicio de cada canción. El presente trabajo se desarrolló en la Comunidad yanesha de Alto Yurinaki, ubicado en el distrito de Perené, provincia Chanchamayo, región Junín (Perú). ${ }^{1}$

Palabras claves: Yaneshas; Canciones ancestrales; Enunciados expresivos; Educación Intercultural Bilingüe

1 Este artículo forma parte de la investigación de mi tesis de maestría en Educación Intercultural Bilingüe del Posgrado de Letras-UNMSM, cuyo asesor es el Dr. Gonzalo Espino Relucé y que desarrollo como parte del grupo de investigación EILA-UNMSM (E21031271). 


\section{Summary}

Ancestral songs are a set of verses, melodies and rhythms typical of a native people. They are diverse: Konareñets, sherareñets, rekërkëñets, etseñets, wellesheñets, po'neshareteñets and are transmitted from generation to generation orally in order to maintain and enrich the culture. We focus our attention on the expressive statements that can be found at the beginning of each song. The present work was carried out in the Yanesha Community of Alto Yurinaki, located in the District of Perené, Chanchamayo Province, Junín Region (Peru).

Keywords: Yanesha; Ancestral Songs; Expressive Statements; Intercultural Bilingual Education

\section{Introducción}

Las canciones ancestrales expresan la cultura yanesha y cada una de ellas expresa nuestra sensibilidad. El objetivo del presente trabajo es registrar los enunciados expresivos en las canciones, revelar su importancia como aporte a la cultura yanesha y su aplicación en la Educación Intercultural Bilingüe, así como detallar el origen, la importancia y la finalidad de las canciones ancestrales.

Una limitación de esta investigación es que no se pudo realizar grabaciones claras y nítidas como se esperaba, porque se grabaron de manera improvisada aprovechando el momento y lugar. Además, cabe mencionar que el sabio con quien se realizó la mayor parte de las grabaciones, falleció durante la emergencia sanitaria que estamos viviendo a nivel nacional.

El pueblo yanesha es una cultura perteneciente a la familia lingüística arawak; habita principalmente en las regiones de Pasco, Junín y Huánuco. Según datos obtenidos del Ministerio de Cultura, la población de las comunidades del pueblo yanesha se estima en 12,931 personas. La investigación se realizó en una de las comunidades pertenecientes a la región Junín, provincia Chanchamayo, distrito de Perené: la comunidad nativa yanesha Alto Yurinaki. Esta comunidad cuenta con alrededor de 400 habitantes entre niños, jóvenes, adultos y ancianos. Hace 5 años se está empezando a revalorar la cultura incentivando desde la escuela para recuperar los saberes y conocimientos de nuestra cultura. 


\section{Definición de palabras clave}

1. Canciones ancestrales: son un conjunto de versos, melodías y ritmos propios de un pueblo originario. Estas se transmiten de generación en generación de forma oral para mantener y enriquecer la cultura.

2. Enunciado expresivo: son aquellos enunciados que expresan emociones y sentimientos como alegría, tristeza, pena, ira, enojo, etc. y se asocian al concepto actos de habla (Searle 1969: 31)

3. Educación Intercultural Bilingüe: Busca formar personas competentes tanto en su lengua materna como en castellano, brindando la posibilidad de conocer su propia cultura y la de los demás para enriquecer sus conocimientos, mejorar su calidad de vida, así como la de toda su comunidad. Para que una educación sea intercultural y bilingüe el docente debe promover la práctica cultural hasta llegar al bilingüismo coordinado.

\section{Análisis y discusión}

Las canciones siempre han estado presentes en la vida de los pueblos originarios. En el pueblo yanesha también se enseñaba y transmitía canciones a los miembros de la familia y comunidad para que no se pierdan con el tiempo; pero, con el transcurrir de los años se ha dejado de lado esta práctica cultural, en la actualidad solamente nuestros abuelos y abuelas son los únicos que aún las recuerdan y practican.

Cabe mencionar que la cultura yanesha tiene muchas canciones ancestrales, la gran mayoría son acompañadas de danzas; es decir, mientras uno está aprendiendo una canción no es necesario danzar, pero cuando ya sabe la canción, debe demostrarlo y practicarlo danzando. Para ello debe participar en los eventos culturales, ya sea en celebraciones comunales, noches culturales, cumpleaños, celebración del rito de la enchozada (Ponapnora), entre otras festividades que se realizan dentro de la comunidad. Estas canciones y danzas se practican de la siguiente manera:

1. Practicada solamente por los varones; konareñets y rekërkëñets.

2. Practicada solamente por las mujeres; sherareñets.

3. Practicada tanto por los varones como las mujeres; etseñets, wellasheñets y pónesháreteñets. 


\subsection{Las canciones ancestrales}

A continuación, se detallará en qué consiste cada canción ancestral:

\section{Konareñets:}

$k o n=$ tambor

konara = danza al son del tambor

eñets= sufijo infinitivo, se usa también en contexto rituales, para identificar canción y danza.

Son canciones dirigidas por los varones, lo cantan acompañado de un tambor, elaborado con piel dura de algún animal. Dos varones van adelante tocando el tambor, sus acompañantes los siguen cantando atrás. Se dan la vuelta por todo el ambiente moviéndose al ritmo de la canción y el tambor. Las mujeres también pueden acompañarlos, pero ellas no tocan el tambor, solo se ubican delante de los varones y abrazados a altura de la cintura, se desplazan cantando y danzando. Cuando los varones se detienen, ellas también deberán detenerse.

\section{Sherareñets:}

sherara $=$ danza acción de ir

eñets $=$ sufijo infinitivo, se usa también en contexto rituales, para identificar canción y danza.

Son canciones únicamente interpretadas por las mujeres donde la voz es el principal instrumento. La mujer que dirige debe saber la canción para guiar a las demás acompañantes, quienes repiten el verso de la canción. Tomados de la mano avanzan realizando formas de columna y círculos. Cada cierto tiempo cambian la posición de las manos que obliga a voltearse a cada una de ellas sobre su mismo lugar, volver a tomarse de la mano y continuar cantando. En otras comunidades, luego de tomarse "de la mano empiezan a cantar, caminar y luego correr por todo el lugar haciendo una especie de circulo" (López 2017: 82).

\section{Rekërkëñets:}

kekërkanets= instrumento del carrizo

eñets = sufijo infinitivo, se usa también en contexto rituales, para identificar canción y danza. 
Son canciones entonadas solamente por los varones al son del carrizo de cinco tubos. Para poder interpretar estas canciones debe haber mínimamente dos personas: el líder y su acompañante, quienes tocan el conjunto de carrizo más cortas. Si hay más personas ellos acompañan con los carrizos más largos. Se desplazarán uno detrás del otro, realizando círculos y columnas por todo el ambiente. Mientras esto ocurre, las mujeres pueden estar entonando la canción de Sherareñets y otro grupo de varones, konareñets. Formándose así una combinación de voces, sonidos y melodías que alegran el ambiente generando una sensación de conexión con nuestros antepasados.

\section{Etseñets:}

Etset $=$ acción de cogerse de las manos y formar una fila.

Eñets= sufijo infinitivo, se usa también en contexto rituales, para identificar canción y danza.

Son canciones donde participan tanto varones como mujeres. El que dirige es un varón y este debe esperar hasta que sus acompañantes se acomoden al lado izquierdo, para ello extiende sus brazos hacia la izquierda y los acompañantes se van acomodando de forma intercalada entre varones y mujeres, extendiendo sus dos brazos y agarrándose de las manos de sus demás compañeros. Una vez acomodados avanzan hacia adelante todos juntos, luego voltea hacia la izquierda y hace que los demás integrantes hagan lo mismo. Esto hace que los acompañantes retrocedan de manera rápida para volver estar alineados. Esta acción hace que los acompañantes que se ubican al final de la fila tambaleen, se suelten y se caigan, provocando risas y diversión de todos.

\section{Wellesheñets y póneshareteñets:}

Estas canciones son interpretadas por mujeres y varones. Antiguamente se cantaba y danzaba luego de ganar una batalla o alcanzar un logro. En estas dos canciones, los participantes cantan y realizan movimientos alrededor del líder. La gran mayoría de las canciones ancestrales detalladas son acompañadas con movimientos, se podría decir que son como las coreografías únicas y propias de la cultura yanesha. 


\subsection{Tres canciones ancestrales}

\begin{tabular}{|c|c|}
\hline \multicolumn{2}{|c|}{ Sherareñets (canción cantada únicamente por las mujeres) } \\
\hline yanesha & castellano \\
\hline $\begin{array}{l}\text { Ye'morrecha santamellarexh ateth } \\
\text { Ye'morrecha santamellarexh ateth } \\
\text { ye'mapreten. Añpa bocasomarnesha } \\
\text { pomorrena nemorrecha. Ama } \\
\text { neñotweñe, tharraña allpon neñoteñpa' } \\
\text { och yepech. } \\
\text { Och llesens ye'noñ yepapar po'wamenk: }\end{array}$ & $\begin{array}{l}\text { Vamos a cantar Santamellarexh como } \\
\text { lo escuchamos. Esta es de Bocaz su } \\
\text { canción, voy a cantar. No lo sabemos } \\
\text { todo, pero lo que sabemos vamos a } \\
\text { cantar. } \\
\text { Permiso, vamos a buscar de nuestro } \\
\text { padre su fuerza. }\end{array}$ \\
\hline $\begin{array}{l}\text { Pha nepapare llesensotnenerr } \\
\text { pellerrotemsatyenyerr. } \\
\text { Pha yápoene phorrerrña } \\
\text { attho yellapenerr, } \\
\text { attho yentennap pepoetareña } \\
\text { errponowañen, apa. } \\
\text { Phapa eno'tsenep, pentañotsenep } \\
\text { pemoeney. } \\
\text { Allpon yeyexhkaten } \\
\text { phapa eñe peñoteñ } \\
\text { Thepa och nemorrechatneñ arr namots, } \\
\text { nemonerresha. } \\
\text { Menkare'tenyet pa' } \\
\text { phapa' peñoteñ. } \\
\text { Phapoerrey atthoch } \\
\text { yokshametemperrpha ñerram pewerra. } \\
\text { Amach phaypoñaterrye yewamenk, } \\
\text { 'nerram pewerrapa' penwerreythe, } \\
\text { pexhoretwerreycha pewerra pentañoth. } \\
\text { The'pa aña nemamnenep llesens } \\
\text { nepapare. } \\
\text { Thepa' och nemorrechnena pesochño. }\end{array}$ & $\begin{array}{l}\text { Tú, mi padre permiso en esta tarde. } \\
\text { Tú nos das la vida } \\
\text { por eso estamos hasta esta tarde, } \\
\text { por eso vemos tu día siempre, } \\
\text { padre. } \\
\text { Tú estás arriba en tu trono, } \\
\text { nos escuchas. } \\
\text { Todo lo que hacemos } \\
\text { tú lo sabes. } \\
\text { En esta tarde voy a hacer cantar a mi } \\
\text { familia, mis hermanas. } \\
\text { Nos están pidiendo, } \\
\text { tú sabes. } \\
\text { Danos para alegrarte cuando vengas. } \\
\text { No nos hagas abandonar nuestra } \\
\text { fuerza, para cuando vuelvas nos } \\
\text { encuentres, } \\
\text { nos llamarás cuando vengas de tu trono. } \\
\text { Hoy, solo te pido permiso, } \\
\text { padre. } \\
\text { Hoy voy a cantar en tu nombre. } \\
\text { (Entrevista a Micaela Francisco López) }\end{array}$ \\
\hline
\end{tabular}


Rekërkëñest (canción cantada solamente por los varones)

\begin{tabular}{|c|c|}
\hline yanesha & castellano \\
\hline
\end{tabular}

Newa the, neñachor yeserrparet. Och yortat añ koshamhñats ñeñth otenet Amayrexh, ñeñthet orrtaterr nomporeshañ Shinyakashopañ. Napa ama nentere, attha e'matyerrnet.

APAÑ̃NA poñoxh enterranoña nomporesha Shinyakashopañ, Tháthepño.

Neñth poeponar nomporesha Shewankoñ, nomporesha Creshtoballeñ, nomporesha Pashcoall, nomporesha Arobe.

Atthothka orrterra añma pokshamhña, amoch chenkëno ñeñth otenet

\section{Amayrexh.}

Napa' ama tama neñoteñe.

Thepa awot moenan patherr... oten apa awoch yegrawa Amayrexh.

Amat ama yeñoche pa' atthach yetpach attha ñeñxho yeñotyen.

Newakaye.
Ahora, yerno vamos a conversar. Vamos a hacer ver esta canción que le llaman Amayrexh, que hizo aparecer mi abuelo Shinyakashopañ.

Yo no le he conocido, solo me hicieron escuchar.

Mi papá sí llegó a conocer a Sinyak en Thethepno.

E1 hijo mayor de mi abuelo

\section{Chibuanco,}

de mi abuelo Cristóbal, de mi abuelo Pascual, mi abuelo Arobe.

De esa manera persista su canción, no se pierda la canción llamada Amayrexh. Y no sé tanto, ahora que uno quiere, me dijo mi papá para grabar Amayrexh.

Aunque no sabemos tanto vamos a intentar lo que sabemos.

A ver. 


\begin{tabular}{|c|c|}
\hline \multicolumn{2}{|c|}{ Elleñets (canción cantada por los varones y las mujeres) } \\
\hline yanesha & castellano \\
\hline $\begin{array}{l}\text { - Apa, poktet penten elleñets } \\
\text { - ah pokte } \\
\text { - masheñ Cros poktewa penten elleñets } \\
\text { - pokte } \\
\text { - allowenes poktewa senteñ elleñets. } \\
\text { - eñe pokte, yapa yenteñ eñe pokte. } \\
\text { Newakaye, atethka oorterra elleñets, } \\
\text { añ orrtaterre Yompor Santo, ñeñth } \\
\text { amchecherre awach Shellememeñ. } \\
\text { Yompor Santo allempo werra chésho } \\
\text { werra chesha. } \\
\text { Xho athpanerran pachor, } \\
\text { ama eñoteñphapoere pachor pa' } \\
\text { pachorñapa' gach poemomor. } \\
\text { Awot och pachor... } \\
\text { Awath acheñ a'ñematerranet ok, ama } \\
\text { acheñe eñalletatyesetethe. } \\
\text { Newa masheñ, och yemorrecha } \\
\text { Theposayrexho ateth nemaprethech } \\
\text { awath apañ Sellanoñ, ñapa xho } \\
\text { e'materet. Año poemorreña ñeñth } \\
\text { oteteth } \\
\text { masheñ Charapillo eñenomarnesha, } \\
\text { yorenakeomarnesha. } \\
\text { Thepa yemneñ och yemorrecha, thepa } \\
\text { och yemorrecha yeta kon. }\end{array}$ & $\begin{array}{l}\text { Papá, ¿estás de acuerdo con elleñets? } \\
\text { - Sí está bien. } \\
\text { - Hermano Cruz ¿estás de acuerdo con } \\
\text { elleñets? } \\
\text { - Está bien. } \\
\text { - Todos ustedes, ¿están de acuerdo con } \\
\text { elleñets? } \\
\text { - Muy bien. Para nosotros está muy } \\
\text { bien. } \\
\text { A ver así se originó elleñets, lo hizo } \\
\text { aparecer Padre Santo, quien le hizo } \\
\text { tranquilizar a Shellememeñ. } \\
\text { Yompor Santo, cuando vino, } \\
\text { vino siendo niño. } \\
\text { Desobedeció a su mamá } \\
\text { No le hizo caso a su mamá } \\
\text { Su mamá le enseñó sus senos. } \\
\text { Le dijo su mamá... } \\
\text { Antes nuestras gentes se juntaron con } \\
\text { los españoles y no hicieron nacer a } \\
\text { gentes. } \\
\text { A ver hermano vamos a cantar } \\
\text { Theposayrexho, como le escuché } \\
\text { antes de mi papá Sellanoñ, el me hizo } \\
\text { escuchar. Dijo que es su canción del } \\
\text { que decían hermano Charapillo, de } \\
\text { Eñeno } \\
\text { Yurinaki. } \\
\text { Ahora queremos cantar, ahora vamos a } \\
\text { cantar tocando el tambor. }\end{array}$ \\
\hline
\end{tabular}

\subsection{Enunciados expresivos en las canciones}

En el presente trabajo ponemos atención básicamente a los enunciados expresivos que están presentes en las canciones ancestrales yanesha. Para obtener toda la información se ha observado, practicado y participado en el canto realizado en las noches culturales (fiestas que se realizan en la noche 
de luna llena) celebraciones, ritos o cualquier actividad que se ha organizado dentro de la institución educativa y comunidad. Estos enunciados no siempre son escuchados, aparecen en la palabra de la sabia o sabio que está dirigiendo la canción, solamente dialoga con sus acompañantes. Estos tienen el privilegio de acceder a la información completa sobre la canción que van a cantar y casi siempre pasa desapercibido por los espectadores

La sabia o el sabio narra brevemente la historia de la canción que se va a cantar, da a conocer la variedad de la canción, si es sherareñets, konareñets, etseñets, wellesheñets. Seguidamente, su nombre específico. Luego narran la historia empezando por quién le enseñó, que les dijeron sobre el origen de la canción, es decir, si el que les enseñó lo escuchó en el río, una laguna, un cerro, una catarata $\mathrm{u}$ otro lugar donde antiguamente nuestros ancestros lograban comunicarse directamente con los seres espirituales o míticos. Se entiende lo anterior debido a que la estrecha relación hombre-naturaleza permitía el contacto con ellos para enseñarles las canciones ancestrales yanesha, así como también lo registra Fedor López (2017: 83): "Los cantos son productos de los mitos, por ende, tienen una estrecha relación al momento de ponerlas en práctica”.

En esta canción los enunciados que encontramos son enunciados expresivos, porque permiten expresar sentimientos, emociones, testimonios, agradecimientos, consejos que se percibe de la siguiente manera:

- Alegría: el hecho de enseñar a cantar les causa una profunda alegría, se evidencia en la voz al empezar a hablar.

- Tristeza y pena: Cuando empiezan a recordar a sus padres, abuelos y otras personas que les enseñaron las canciones.

- Reverencia: Al momento de pedir permiso para cantar. Algunos hasta realizan un rezo solicitando premiso a Yompor Parets (dios del pueblo yanesha), para entonar la canción, ya que consideran que las canciones aprendidas serán para él.

- Nostalgia: Las palabras vertidas conllevan a una conexión con nuestros antepasados. Al meditar y analizar las palabras, te llevan a un estado emocional de nostalgia. Se ha observado a muchos sabios y sabias llorar mientras están realizando el acto del habla o al momento de cantar también.

- Quejas: se evidencia, por ejemplo, cuando una de las sabias al mencionar que no es feliz, porque ninguna de sus hijas tiene el interés de aprender las canciones. 
- Preocupación: una sabia al mencionar que si sus hijas no aprenden las canciones, el día que ella muera va a desaparecer también las canciones.

- Consejo: Siempre aconsejan a los oyentes a seguir practicando las canciones para que no se pierdan y perduren en el tiempo.

Luego del análisis se puede afirmar que todas las canciones yanesha tienen un origen, por lo tanto, no solo debe transmitirse los versos, sino también toda la información completa. Eso lo encontramos gracias al acto de habla que ha estado presente en las canciones.

\section{Discusión}

Los enunciados expresivos están presentes en nuestras comunicaciones. Todas las personas lo usamos de una u otra manera. Como menciona Austin, porque hay muchísimas funciones o manera en que usamos el lenguaje, y constituye una gran diferencia para nuestro acto en algún sentido (Austin 1990: 143). Tal es el caso de los enunciados expresivos que encontramos antes de iniciar una canción en la lengua yanesha. Lo más resaltante es que se encuentra información cultural importante en los enunciados expresivos que muchas veces han pasado desapercibidas. Como identifica Rosberly López (2016) las "Condiciones de sinceridad: expresan lo que el hablante siente, o debe sentir, al realizar el acto ilocutivo", para luego precisar que los "Actos expresivos: expresan una actitud psíquica del hablante respecto a la realidad caracterizada en el contenido proposicional. Su intención ilocutiva es la de expresar su condición de sinceridad".

A esto debemos agregar las fuentes. Algunas canciones analizadas fueron grabadas hace muchos años, las que han sido facilitadas para este estudio, con la finalidad de enriquecer la información, asimismo, se ha complementado con grabaciones y vídeos no mayores a cinco años de antigüedad. La persona que nos facilitó estas canciones es el profesor Marlon López Hoyos de la comunidad de Alto Yurinaki. Allí encontramos solo apodos en yanesha de las personas quienes fueron grabadas, por ejemplo: Kamoeba, Thosen, Thaka. En las recopilaciones de años atrás se evidencian con mayor frecuencia y constancia, valiosa información; mientras que, en la actualidad, son tomadas a la ligera, y en muchos casos se obvian; permitiendo que se vaya perdiendo poco a poco esta práctica como una parte esencial de las canciones. En consecuencia, afectaría la esencia de las canciones; en lo sucesivo podría desaparecer, y con ello, se perdería el sentido de las canciones ancestrales. 
La lengua yanesha, en la actualidad, está en peligro de extinción, no solo por el número reducido de sus hablantes sino porque la mayoría de los niños han dejado de aprender a hablar en el idioma ancestral dando prioridad al castellano.

Los enunciados expresivos que se encuentran en las canciones ancestrales, permitirán que los y las niñas, jóvenes, adultos y toda la comunidad en general, conozcan el origen de las canciones, a sus abuelos quienes les enseñaron y toda la información que brindan los sabios y sabias al inicio. Para que vuelvan a dar importancia a las canciones, lo pongan en práctica contribuyendo a hablar la lengua yanesha. Veamos un ejemplo de ello en el siguiente cuadro:

\begin{tabular}{|c|c|}
\hline \multicolumn{2}{|c|}{ Rekërkëñest (canción cantada solamente por los varones) } \\
\hline yanesha & castellano \\
\hline $\begin{array}{l}\text { Newa the, neñachor yeserrparet. } \\
\text { Och yortat añ koshamhñats ñeñth } \\
\text { otenet Amayrexh, ñeñthet orrtaterr } \\
\text { nomporeshañ Shinyakashopañ. } \\
\text { Napa ama nentere, } \\
\text { attha e'matyerrnet. } \\
\text { Apañña poñoxh enterranoña } \\
\text { nomporesha Shinyakashopañ, } \\
\text { Tháthepño. } \\
\text { Neñth poeponar nomporesha } \\
\text { Shewankoñ, } \\
\text { nomporesha Creshtoballeñ, } \\
\text { nomporesha Pashcoall, } \\
\text { nomporesha Arobe. } \\
\text { Atthothka orrterra añma } \\
\text { pokshamhña, amoch chenkëno ñeñth } \\
\text { otenet Amayrexh. } \\
\text { Napa ama tama neñoteñe. } \\
\text { Thepa awot moenan patherr... oten } \\
\text { apa awoch yegrawa Amayrexh. } \\
\text { Amat ama yeñoche pa' atthach } \\
\text { yetpach attha ñeñxho yeñotyen. } \\
\text { Ñewakaye. }\end{array}$ & $\begin{array}{l}\text { Ahora, yerno vamos a conversar. } \\
\text { Vamos a hacer ver esta canción que le } \\
\text { llaman Amayrexh, que hizo aparecer } \\
\text { mi abuelo Shinyakashopañ. } \\
\text { Yo no le he conocido, } \\
\text { solo me hicieron escuchar. } \\
\text { Mi papá sí llegó a conocer a Sinyak } \\
\text { en Thethepno. } \\
\text { El hijo mayor de mi abuelo } \\
\text { Chihuanco, } \\
\text { de mi abuelo Cristóbal, } \\
\text { de mi abuelo Pascual, } \\
\text { mi abuelo Arobe. } \\
\text { De esa manera persista su canción, } \\
\text { no se pierda la canción llamada } \\
\text { Amayrexh. } \\
\text { Y no sé tanto, } \\
\text { ahora que uno quiere, me dijo mi } \\
\text { papá para grabar Amayrexh. } \\
\text { Aunque no sabemos tanto vamos a } \\
\text { intentar lo que sabemos. } \\
\text { A ver. }\end{array}$ \\
\hline
\end{tabular}


Con ese ejemplo afirmamos lo redactado en el libro del CILA-UNMSM, para que crezcan bien. La lengua está ligada a la cultura e involucra relaciones sociales, procesos históricos y toda una inaprensible cantidad de redes que tejen los sujetos de un grupo en la construcción de su cultura (CILA-UNMSM 2012).

Las canciones ancestrales permiten activar la memoria de nuestros sabios y sabias, quienes tienen muchos conocimientos y saberes que van fluyendo antes, durante y después de cantar. También, permiten recuperar nuestra cultura que poco a poco se está perdiendo por la falta de práctica. Al mismo tiempo volver a las formas de expresión de nuestra lengua, recuperando palabras y frases que ya no se suelen escuchar.

Se pudo notar que la gran mayoría de los actos de habla presentes en las canciones son enunciados expresivos, ya que expresan sentimientos y emociones como felicidad, alegría, tristeza, melancolía, pena, entre otros.

\section{Conclusiones}

Las canciones yanesha, especialmente las ancestrales, se caracterizan por su carácter expresivo, porque permiten que los enunciados expresivos sean una mezcla de emociones y sentimientos de parte de las personas que la entonan y escuchan.

En la actualidad, estos enunciados expresivos ya no se evidencian con mayor frecuencia en las canciones, como lo solían hacer nuestros ancestros. Se puede afirmar que se está dejando de transmitir esa parte fundamental, lo que conllevaría a la pérdida de la información cultural necesaria para que las canciones no lleguen vacías a los aprendices; evitando su pérdida con el transcurrir del tiempo.

Los enunciados expresivos se pueden incorporar en la Educación Intercultural Bilingüe, teniendo en cuenta el enfoque del área de lengua originaria como segunda lengua: incorpora las prácticas sociales del lenguaje y la perspectiva sociocultural. Donde menciona que el aprendizaje de segundas lenguas se sustenta en el enfoque comunicativo alimentado por el enfoque sociocultural, que concibe el discurso escrito u oral como una práctica social, una forma de acción entre las personas que se articula a partir del uso de la lengua en diversas situaciones comunicativas. Esta competencia comunicativa se logra con la realización de distintas actividades de la lengua que comprenden la comprensión y producción oral y escrita. Asimismo, incorpora las prácticas sociales del lenguaje, porque las situaciones comunicativas no están aisladas; 
forman parte de las interacciones que las personan usan cuando participan en la vida social y cultural. A partir de estas prácticas, los estudiantes vivencian de manera permanente los usos y posibilidades del lenguaje, para dominarlo progresivamente. Además, es sociocultural, porque estas prácticas del lenguaje se encuentran situadas en contextos sociales y culturales diversos y generan identidades individuales y colectivas.

Se podrá trabajar con la competencia uno. Se comunica oralmente en su lengua originaria como segunda lengua, que implica desarrollar las siguientes capacidades:

- Obtiene información del texto oral

- Infiere e interpreta información del texto oral

- Adecúa, organiza y desarrolla las ideas de forma coherente y cohesionada

- Utiliza recursos no verbales y paraverbales de forma estratégica

- Interactúa estratégicamente con distintos interlocutores

- Reflexiona y evalúa la forma, el contenido y contexto del texto oral.

Empezar a trabajar con la primera competencia y después continuar con la competencia dos: Lee diversos tipos de textos escritos en lengua originaria como segunda lengua; y la competencia tres: Escribe diversos tipos de textos en lengua originaria como segunda lengua.

Dar el hincapié a los sabios y sabias que brinden toda la información que contienen las canciones ancestrales, a nuestros estudiantes. Pues se considera muy importante para fortalecer, practicar, revalorando y rescatar los conocimientos y saberes ancestrales encaminándonos hacia el rescate de una de nuestras riquezas culturales. 


\section{Referencias bibliográficas}

Austin, John. Cómo hacer cosas con palabras. Palabras y acciones. Compilado por J. O. Urmson. Barcelona: Paidós Ediciones, 1990.

CILA-UNMSM. Para que crezcan bien. Crianza y capacidades en niñas y niños ashaninka, shipibo y yine del Ucayali. Lima: UNICEF/CILA-UNMSM, 2012.

López, Lito Fedor. Factores que permiten la compilación de los mitos tradicionales Yánesha en la Institución Educativa Bilingüe $N^{\circ}$ 34511. Sector centro Conaz, comunidad nativa 7de Junio Villa América, 2016. Tesis de Licenciatura. Lima: Universidad Católica Sedes Sapientiae, Facultad de Ciencias de la Educación y Humanidades, $2017<$ http://repositorio.ucss.edu. pe/bitstream/handle/UCSS/392/Lopez_Lito_tesis_bachiller_2017. pdf?sequence $=1$ \&isAllowed $=y>$.

López, Rosberly. "Los actos de habla en el discurso publicitario de la prensa rural escrita: el caso del periódico Mi Cantón”, RECLAL: Revista del Centro de Investigaciones de la Facultad de Filosofía y Humanidades. Vol. 7, No. 10, diciembre 2016, p. 01-17. <https://dialnet.unirioja.es/servlet/ articulo?codigo $=7323568>$ (15 marzo, 2021).

Searl, John. Actos de habla. Ensayo de filosofía del lenguaje. Trad. Luis M. Valdés Villanueva. Barcelona: Ediciones Cátedra, Agostini, 1994.

\section{Entrevistas a sabios/sabias}

Micaela Francisco López (78), Yanesha de la comunidad nativa Alto Yurinaki, (Perené, Chanchamayo, Junín); entrevista realizada el 15 de octubre del 2020.

Francisco Quinchuya Gómez (1949-2020), Yanesha de la comunidad nativa Alto Yurinaki, (Perené, Chanchamayo, Junín); entrevista realizada el 10 de mayo del 2020. 